Review

\title{
Melatonin Signaling and Its Modulation of PfNF-YB Transcription Factor Expression in Plasmodium falciparum
}

Wânia Rezende Lima ${ }^{1}$, Anthony A. Holder ${ }^{2}$ and Célia R. S. Garcia ${ }^{1, *}$

1 Departamento de Fisiologia, Instituto de Biociências, Universidade de São Paulo, São Paulo 05508900, Brazil; E-Mail: wrlima@ib.usp.br

2 Division of Parasitology, MRC National Institute for Medical Research, The Ridgeway, Mill Hill, London NW7 1AA, UK; E-Mail: aholder@nimr.mrc.ac.uk

* Author to whom correspondence should be addressed; E-Mail: cgarcia@usp.br; Tel.: +55-11-3091-7518, Fax: +55-11-3091-8095.

Received: 19 May 2013; in revised form: 23 June 2013 / Accepted: 25 June 2013 / Published: 1 July 2013

\begin{abstract}
Malaria is one of the most severe tropical infectious diseases. More than 220 million people around the world have a clinical malaria infection and about one million die because of Plasmodium annually. This parasitic pathogen replicates efficiently in its human host making it difficult to eradicate. It is transmitted by mosquito vectors and so far mosquito control programs have not effectively eliminated this transmission. Because of malaria's enormous health and economic impact and the need to develop new control and eventual elimination strategies, a big research effort has been made to better understand the biology of this parasite and its interactions with its vertebrate host. Determination of the genome sequence and organization, the elucidation of the role of key proteins, and cell signaling studies have helped to develop an understanding of the molecular mechanisms that provide the parasite's versatility. The parasite can sense its environment and adapt to benefit its survival, indeed this is essential for it to complete its life cycle. For many years we have studied how the Plasmodium parasite is able to sense melatonin. In this review we discuss the melatonin signaling pathway and its role in the control of Plasmodium replication and development.
\end{abstract}

Keywords: melatonin; malaria; signaling modulation; Plasmodium 


\section{Introduction}

Malaria is caused by protozoan parasites of the genus Plasmodium that have impacted survival and driven human evolution throughout history. Whilst Plasmodium parasites infect some reptiles, birds and mammals, including primates, it is accepted that 10,000 years ago malaria impacted human survival during the beginning of agriculture [1]. Human malaria originated in Africa and extended to all other populated continents, but nowadays it is predominantly located in tropical regions, comprising 104 malaria-endemic countries according to the World Health Organization (WHO) database [2]. There are five species that naturally infect humans, of which $P$. falciparum and $P$. vivax are most prevalent. More than 220 million people suffer clinical malaria annually with over one million deaths, largely due to $P$. falciparum infection.

The human host is infected by the bite of an Anopheles mosquito, which delivers the sporozoite form of the parasite. Sporozoites migrate to the liver and differentiate into multinucleate exoerythrocytic schizonts, which then release merozoites that initiate the asexual blood stage of development. The merozoite invades a red blood cell (RBC) to commence intracellular development through the uninuclear ring and trophozoite stages that precede nuclear division in the schizont stage. The multinucleate schizont is formed and then division of the cytoplasm in late schizogony (the segmenter stage) forms new merozoites that are released to invade fresh RBC and continue the cycle [3]. This intraerythrocytic cycle in mammals takes approximately 24,48 or $72 \mathrm{~h}$ depending on the parasite species and the host. For example in P. falciparum, one ring stage form may replicate and differentiate into 16 to 32 daughter merozoites [4,5] in one asexual cycle that lasts about $48 \mathrm{~h}$. Schizont maturation and merozoite release occur relatively synchronously resulting in periodic fever, and further physiological complications as the disease evolves, including headaches, nausea and vomiting, anemia, renal failure [6], respiratory distress and in a few cases, cerebral malaria [7,8]. Transmission back to a mosquito is achieved by some intracellular parasites differentiating into male and female gametocytes that, if taken up in a blood meal, differentiate into male and female gametes in the mosquito gut allowing fertilization and infection of the insect. The periodicity and synchronicity of the asexual cycle is modulated in vivo according to the circadian rhythm of the host. For example the temperature cycle of the host [9] or the timing of the light-dark cycle [10] can be manipulated in experimental systems to change the pattern of development of the parasite.

The need to obtain insights into how to control or eliminate Plasmodium infection has promoted many researchers to try and understand better the parasite's molecular machinery. Genome sequencing has provided tools to study and analyze the parasite's biochemistry and physiological mechanisms. The $P$. falciparum genome sequence was determined ten years ago [11] since when many protein families have been discovered and characterized [12,13]. Studies on the importance of signaling pathways, gene regulation, and the mode of action of antimalarial drugs have contributed enormously to our understanding of how the parasite machinery works [14].

Melatonin ( $N$-acetyl-5-methoxytryptamine) is a tryptophan-derived metabolite that participates in several physiological activities, not only synchronizing the circadian rhythm, but also playing a role in sleep, free radical scavenging, immune-regulation and as an antibacterial agent [15-19]. In vertebrates, melatonin has also been shown to regulate transcription factors, phosphorylation of cAMP-responsive element binding protein, and c-Fos expression [20]. Melatonin is also found in plants and unicellular 
organisms [21-24]. In this review we focus on the role of melatonin in the intraerythrocytic cycle of Plasmodium development, and highlight its potential to be targeted to develop antimalarial drugs.

\section{Melatonin Signaling: Calcium and cAMP Generation in P. falciparum and $P$. chabaudi}

Melatonin signaling controls a variety of physiological processes, some of which are influenced by the light/dark circadian cycle [25]. The circadian cycle is the period of one day (24 h) in which to complete activities of the biological cycle of an organism. One function of this system is adjustment of the biological clock, sleep and appetite control. A pacemaker, the suprachiasmatic nucleus (SCN), referred to as a master clock in mammals connects to a hormonal network to orchestrate the circadian rhythm [25-28]. Undoubtedly, the melatonin hormone is part of this network. Melatonin, plays a role in the circadian cycle of malaria parasite development, and has been shown to modulate the asexual cycle of both $P$. falciparum and $P$. chabaudi $[29,30]$. Hotta and collaborators elegantly demonstrated that the synchronization of parasite development is lost in pinealectomized mice, whereas melatonin administration restored synchronicity in $P$. chabaudi [29].

Melatonin precursors (serotonin, $N$-acetyl serotonin (NAS), and tryptophan) and derivatives $(N(1)$-acetyl-N(2)-formyl-5-methoxykynuramine (AFMK)) also modulate the parasite cycle and maintain the synchronicity of $P$. falciparum development [31,32]. In mammals, the asexual blood stage development of malaria parasites is variable between the species (based on 24, 48 or $72 \mathrm{~h}$ cycles), but is very synchronous. This synchronicity of parasite development is finely regulated in vivo, but if the parasite is cultured in vitro it is quickly lost. This effect can be explained by the absence of indoleamine hormone in the culture. Interestingly the peak of melatonin delivery in vivo overlaps with schizont maturation, merozoite release and $\mathrm{RBC}$ reinvasion in rodent parasites [29] suggesting that the Plasmodium parasite can sense melatonin levels. But how can melatonin modulate the parasite cell cycle? We have proposed that the presence of exogenous melatonin transduces a signal by coupling through an as yet unidentified Plasmodium melatonin receptor that activates phospholipase C (PLC). PLC induces the production of inositol triphosphate $\left(\mathrm{IP}_{3}\right)$, which is a second messenger able to mobilize intracellular $\mathrm{Ca}^{2+}$ from subcellular compartments, leading to a rise in cytosolic $\mathrm{Ca}^{2+}$ concentration through open ER-localized $\mathrm{IP}_{3}$-sensitive $\mathrm{Ca}^{2+}$ channels in $P$. falciparum $[29,33]$. It was demonstrated that U73122 (PLC inhibitor) obstructed the cAMP increase indicating a cross talk between the $\mathrm{Ca}^{2+}$ and cAMP pathways in the parasite [34]. This melatonin signaling produces a complex cascade of events also involving a rise in cyclic AMP [34], as illustrated in Figure 1. In Plasmodium, cAMP signaling participates in several biological processes through activation of cAMP-dependent protein kinase A (PKA). In P. falciparum a downstream PKA response is important in parasite growth and the cell cycle, modulation of anion conductance, and erythrocyte invasion [35-37]. Recently, PKA was implicated in the control of parasite motility and cell invasion through phosphorylation of the glideosome components, myosin A and GAP45 and of $\mathrm{Ca}^{2+}$ dependent protein kinase-1 (CDPK1). It was suggested that the involvement of both PKA and CDPK1 provides a way of coordinating cAMP and $\mathrm{Ca}^{2+}$ fluxes to control motor activity and invasion [38]. The family of CDPKs such as CDPK1 provides a way to further coordinate the biological processes they control with $\mathrm{Ca}^{2+}$ fluxes in the cell [39]. 
Figure 1. Melatonin molecular signaling pathways in Plasmodium. Melatonin (MLT) crosses the erythrocyte (RBC) surface membrane (EM) and the parasitophorous vacuolar membrane (PVM) into the parasitophorous vacuole (PV). Plasmodium senses MLT from the $\mathrm{RBC}$ and a cascade of signaling is initiated through an as yet unidentified melatonin receptor located in the parasite plasma membrane (PM) (?). Melatonin signaling activates phospholipase $\mathrm{C}$ (PLC) that induces the production of inositol triphosphate $\left(\mathrm{IP}_{3}\right) . \mathrm{IP}_{3}$ is able to mobilize intracellular $\mathrm{Ca}^{2+}$ from the endoplasmic reticulum (ER) leading to a rise in cytosolic $\mathrm{Ca}^{2+}$ concentration through open ER-localized $\mathrm{IP}_{3}$-sensitive $\mathrm{Ca}^{2+}$ channels. In addition, melatonin signaling activates adenylyl cyclase (AC) producing an increase in cAMP level and further activation of protein kinase A (PKA). PKA is involved in controlling the balance of gene expression in the nucleus $(\mathrm{N})$. Melatonin is also implicated in the activation of gene transcription for the UPS (ubiquitin proteasome system) machinery. Protein kinase 7 (PfPK7) seems to participate in the melatonin signaling pathway since parasites with a knockout of this kinase are not responsive to melatonin treatment, as measured by parasite intraerythrocytic stage distribution and activation of a subset of genes involved in UPS. However, how PfPK7 plays its role in melatonin signaling has not been identified yet. Most recently, it has been shown that melatonin increases ubiquitination of PfNF-YB transcription factor and increases its expression.

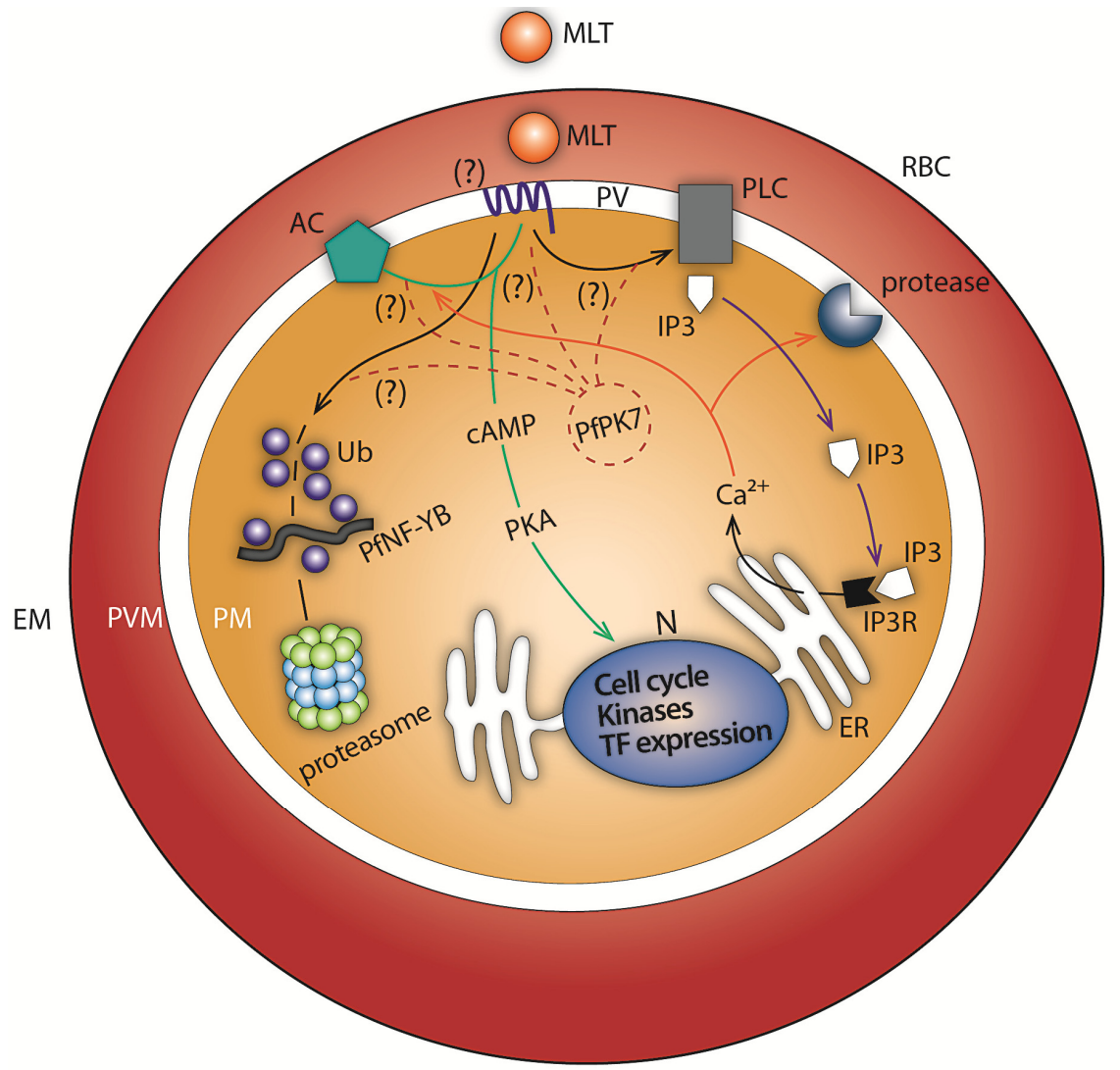

The involvement of $\mathrm{Ca}^{2+}$ in the regulation of long-term cell adaptation through its ability to control gene expression has been considered a key feature in the biology of mammalian cells [40]. For Plasmodium, $\mathrm{Ca}^{2+}$ signaling has been reported by several labs to be crucial to cellular activities and the parasite life cycle [41-48]. 


\section{Melatonin Modulates the Expression of a Subset of Genes of the Ubiquitin Proteasome System (UPS) in P. falciparum}

The UPS machinery is highly conserved from yeast to human and is required for targeted degradation of protein in eukaryotic cells. The UPS pathway is characterized as a major catabolic process that results in the proteolysis of both cytosolic and nuclear proteins in an extra-lysosomal compartment - the proteasome [49-53]. As a result of its protein degradation activity, UPS plays a key role in the regulation of development, differentiation, proliferation, cell cycling, apoptosis, gene transcription, signal transduction, senescence, antigen presentation, inflammation, and the stress response [54-58].

Proteins are targeted for destruction first by covalent modification with ubiquitin, and then the ubiquitinated protein is guided to the $26 \mathrm{~S}$ proteasome, a large multicatalytic multisubunit protease complex, which constitutes the central proteolytic machinery of the UPS. A group of three enzymes, $\mathrm{E} 1, \mathrm{E} 2$ and $\mathrm{E} 3$ is essential for the initial protein targeting during this process. E1 is an ubiquitin-activating enzyme that binds and activates ubiquitin through a thioester, in a step that requires energy from ATP. Then the ubiquitin is transferred to the active site cysteine of E2, an ubiquitin-conjugating enzyme, and finally the ubiquitination cascade ends with the covalent linkage created by E3 ubiquitin-protein ligases in which the carboxy-terminal glycine of ubiquitin forms an isopeptide bond to the side chain of a lysine residue of the target protein. The process of ubiquitin-mediated target protein delivery to the $26 \mathrm{~S}$ proteasome may involve multiple cycles of ubiquitination resulting in the polyubiquitin chains that serve as a recognition signal for the $26 \mathrm{~S}$ proteasome [49,50]. A subset of E3 ligases important in protein recognition involves the cullin and F-box proteins [59].

In Plasmodium, very little work has been done regarding the characterization of the parasite's ubiquitin machinery [60]. However, due the important role of UPS in the cell, some studies have examined and predicted by in silico analysis a source of ubiquitin moieties in Plasmodium. For example, the polyubiquitin gene PF3D7_1211800 that codes for five conserved ubiquitin repeats, was identified [61-63]. The two ubiquitin fusion proteins PfUBS27 and PfUBL40 (PF14_0027 and PF13_0346, respectively) contain an ubiquitin moiety at their N-terminus [62]. Moreover, one conserved ubiquitin domain was identified in PF08_0067, a protein that is believed to be part of an endoplasmic reticulum-associated protein degradation (ERAD) 3-like pathway [63]. Further investigation, reveals other components of the P. falciparum ERAD system: one ubiquitin-activating E1 enzyme (UBA1), a ubiquitin-conjugating E2 enzyme (UBC), and a ubiquitin E3 ligase (Plasmodium HRD1). It was demonstrated that E1 and E2 localize to the cytosol whereas the E3 ubiquitin ligase is found within the ER membrane, consistent with their respective functions in the ERAD pathway [60].

Research in plant biology has revealed that the auxin hormone signal is sensed by components of the UPS that are commonly found in all eukaryotic cells. The auxin signaling pathway takes direct control of an E3 ligase and signals by promoting the ubiquitination and degradation of a set of transcriptional repressors $[64,65]$. Auxin is one of the most abundant natural plant molecules and its structure, as indole-3-acetic acid (IAA) is related to that of serotonin and melatonin. The biosynthesis of melatonin and IAA shares some common precursors, such as tryptophan and tryptamine [66,67]. Therefore, we were interested to investigate whether the melatonin signaling pathway acts on the $P$. falciparum UPS machinery. We demonstrated at the transcriptional level that melatonin treatment 
up-regulates genes coding for UPS components and that luzindole, a melatonin antagonist, inhibits the modulation of UPS transcription [68]. The transcript levels of E1 ubiquitin-activating enzyme, putative UBA1 and 2 (PFL1790w), E3 ubiquitin-protein ligase (Mal8P1.23), 26S proteasome regulatory subunit (RPN6, PF14_0025) and cullin-like protein (PF08-0094) increased after treatment with melatonin, thereby promoting ubiquitination of target proteins. Moreover, it was found that melatonin signaling involves an atypical protein kinase, PfPK7 [69,70], since melatonin treatment of P. falciparum parasites containing a disrupted $p k 7$ gene does not affect regulation of UPS genes. In addition, melatonin treatment of the $p k 7$ disrupted parasite did not affect the ratio of asexual stages and the increase in cytosolic $\mathrm{Ca}^{2+}$ was strongly diminished. Re-introduction of a functional copy of the $p k 7$ gene into the defective $p k 7$-disrupted parasites restored the sensitivity to melatonin-induced alterations in UPS gene transcription. The importance and implications of melatonin signaling pathways modulating the UPS is a new area that deserves to be explored more fully since UPS is a crucial process central to cell development. Most recently, melatonin signaling was implicated in enhancing the ubiquitination of $\alpha$-synuclein monomers and aggregates in the hippocampus of C57/BL6 mice. It was suggested that melatonin may exert its neuroprotection by inhibiting KA-induced autophagy and a subsequent mitochondrial loss as well as reducing $\alpha$-synuclein aggregation by ubiquitination in the CNS [71].

\section{Melatonin Signaling Modulates PfNF-YB Transcription Factor Expression in P. falciparum}

In vertebrates, melatonin has a well-known regulatory role on the circadian rhythm, but beyond that it plays other biological functions in various cell types and peripheral tissues (for review see [72]). In different tissues and organs, melatonin has been described to act as a paracrine and also as an intracrine and autocrine agent with overall homeostatic functions and pleiotropic effects that include cell protection and survival. One of the roles of melatonin signaling is modulating gene regulation and expression. This indolamine is responsible for the control of transcription factor NF-YB-dependent genes including, among others, those coding for inflammatory mediators and antioxidant enzymes [73]. It has been demonstrated that melatonin signaling down-regulates the expression of Rex-1 and Oct4 transcription factors in murine embryonic stem cells [74].

The finding that melatonin controls the Plasmodium cell cycle and regulates transcription factor expression in vertebrates stimulated us to study the effect of the melatonin-induced signaling cascade upon regulation of gene expression in Plasmodium. Indeed, our group showed for the first time that the malarial transcription factor, PfNF-YB (PF11_0477), is regulated by melatonin signaling in the trophozoite stage of $P$. falciparum. Although PfNF-YB is expressed throughout the intraerythrocytic stages (ring, trophozoite and schizont forms), it was not examine whether PfNF-YB is ubiquitinated in the ring stage, since melatonin signaling does not affect this stage where the metabolic activity is lower compare to trophozoite and schizont forms. In addition, it was shown that melatonin affected the post-translational modification of PfNF-YB by ubiquitination. The melatonin cascade was able to increase PFNF-YB expression by two-fold and increase PFNF-YB ubiquitination in P. falciparum [75] (Figure 1). How melatonin signaling can modulate PfNF-YB expression through the cAMP cascade can be suggested since we observed that the cAMP second messenger can modulate PfNF-YB expression itself. Therefore, melatonin probably uses cAMP second messenger to regulate PfNF-YB expression. In contrast, melatonin signaling can upregulate mRNA expression of UPS related 
genes [68]. However, it has not been described yet whether melatonin signaling uses the same cascade to transcriptionally regulate genes or induce posttranslational protein modification. It was observed that melatonin signaling regulation of UPS genes is protein kinase 7 (PK7) dependent. Whether or not PK7 is required for regulation of PfNF-YB expression by melatonin deserves to be addressed.

PfNF-YB is the CCAAT-box-binding subunit B of the NF-Y complex and is conserved from yeast to human [76]. In mammals NF-YB binds to the CCAAT motif of several gene promoters during the $\mathrm{G} 2 / \mathrm{M}$ phase of the cell cycle, such as genes coding for topoisomerase IIa, cyclin B1, CDC25C, E2F, $\mathrm{CDC} 2$ and thymidine kinase to modulate their expression [77-79]. Once the diverse functions of PfNF-YB in P. falciparum have been elucidated, the role played by PfNF-YB in melatonin signaling pathway modulation will be better understood. So far few other transcription factors have been described in P. falciparum and therefore the action of melatonin in modulation of other transcription factors has been very poorly investigated in Plasmodium. Melatonin may be involved in many other cellular pathways in addition to those already known in Plasmodium. We propose that the downstream molecular mechanism of melatonin signaling includes the modulation of gene expression for the UPS machinery.

Moreover, cAMP signaling differentially modulates PfNF-YB expression during intraerythrocytic stage in $P$. falciparum. In the ring stage a cAMP analogue decreases PfNF-YB expression while in trophozoite stage, the analogue increases PfNF-YB expression [75]. The PfNF-YB modulation by cAMP signaling can be explained by the fact that the cAMP response induces translocation of the PKA catalytic subunit to the nucleus where PKA modulates a variety of transcriptional regulators. The catalytic subunit gene of cAMP-dependent protein kinase (Pfpka-c) exists as a single copy in P. falciparum. Pfpka-c has been described as being expressed at high level in the pathogenic sexual stages and in the asexual parasites. PfPKA activity can be readily detected in schizonts and the parasite enzyme can be stimulated by cAMP [35].

\section{Melatonin Blockers as Potential Antimalarial Drugs}

Melatonin is synthesized in the pineal gland during the night mainly due the stimulation of the enzyme, arylalkylamine $N$-acetyltransferase (AANAT) in response to the photoneuroendocrine system. For melatonin biosynthesis, the amino acid tryptophan is converted into serotonin, which is then metabolized into melatonin by two different enzymes: AANT and hydroxyindole- $O$-methyltransferase (HIOMT). AANT $N$-acetylates serotonin to form $N$-acetylserotonin, which in turn undergoes $O$-methylation by HIOMT enzyme, to form melatonin [80,81]. In addition, the SCN regulates melatonin production and AANAT activity by a norepinephrine neurotransmitter that acts in a circadian manner during the night. The norepinephrine activates the $\beta 1$ - and $\alpha 1$-adrenergic receptors. The first, the $\beta 1$-adrenergic receptor, increases the intracellular cAMP resulting in activation of PKA, both of which stimulate AANAT and melatonin generation. The second, $\alpha 1$-adrenergic receptor activation causes an increase in $\mathrm{Ca}^{2+}$ influx by releasing $\mathrm{Ca}^{2+}$ ions from intracellular stores in pinealocyte cells $[82,83]$. In exposure to bright light AANAT is degraded and consequently melatonin production is inhibited [84].

During the night the neurohormone melatonin is produced and is spread throughout the body via the circulation. Via the bloodstream melatonin reaches the cells of various organs and is found distributed in lymphocytes, the thymus, skin, the eyes, the gastrointestinal tract, and the bone marrow (reviewed 
in [85]). Although it freely diffuses through all biological membranes, melatonin internalization is also receptor-mediated. Four receptors have been described that enhance melatonin internalization into cells. Melatonin binds with high affinity to melatonin receptor $\mathrm{MT}_{1}$, with a dissociation constant $(\mathrm{Kd})<200 \mathrm{pM}[86]$. The $\mathrm{MT}_{2}$ receptor is very similar to $\mathrm{MT}_{1}$ sharing $60 \%$ amino acid sequence identity [87]. A third melatonin-related receptor, known as GPR50, shares $45 \%$ amino acid sequence identity with $\mathrm{MT}_{1}$ and $\mathrm{MT}_{2}$ [88] and seems to form a heterodimers with $\mathrm{MT}_{1}$ and $\mathrm{MT}_{2}$ [89]. The $\mathrm{MT}_{3}$ melatonin receptor (previously called ML-2) binds to melatonin with lower affinity (Kd 0.9-10 nM). $\mathrm{MT}_{1}$ and $\mathrm{MT}_{3}$ receptors are coupled to $\mathrm{G}$ proteins [90]. Melatonin also interacts with nuclear receptors belong to the RZR/ROR subfamily which by alternative splicing creates the ROR $\alpha, R Z R \beta$ and $\mathrm{ROR} \gamma$ receptors [91].

How can understanding Plasmodium melatonin signaling contribute to the discovery of new antimalarial drugs? This idea is based on the findings that melatonin contributes to the control of parasite replication and survival and therefore these pathways may be targeted and blocked. Melatonin antagonists have been identified, and one of the most powerful is luzindole [92]. Luzindole has a higher affinity for $\mathrm{MT}_{2}$ than $\mathrm{MT}_{1}$, by approximately 11- to 25-fold [90,93]. This antagonist has been used by several researchers to show the effect of melatonin, for instance describing the blockage of dopamine release in rabbit retina [94]. Luzindole has been described as abolishing the action of melatonin on Plasmodium $[32,68,95,96]$. However, it is still unknown whether the Plasmodium melatonin receptor works through a GPCR signaling mechanism. Luzindole blocks melatonin action and interferes with synchronization of both P. falciparum and P. chabaudi in vitro. Melatonin signaling activates PLC leading to an increase of $\mathrm{Ca}^{2+}$ and $\mathrm{IP}_{3}$ generation $[29,30,33]$, and this effect is abolished in the presence of both luzindole and U73122 (an inhibitor of phospholipase C). Melatonin directly modulates the parasite-host interaction, for example in mice melatonin suppresses hepatocyte apoptosis during Plasmodium yoelii infection by preventing oxidative stress. The mitochondrial pathway of apoptosis, which plays the critical role, is blocked by melatonin [97]. However, asynchronous $P$. berghei and $P$. yoelii are insensitive to the effect of melatonin, both with respect to $\mathrm{Ca}^{2+}$ flux and cell cycle modulation [98].

Parasite synchronization with the circadian rhythm is an evolutionary adaptation $[99,100]$ to evade the immune system and to deliver gametocytes at the optimal time for uptake by feeding mosquitoes [9]. In addition, it was shown that when parasites lose synchronicity the protection provided by classical antimalarial drugs is enhanced at suboptimal doses [95]. These represent new avenues of research for the development of new combinations of pharmacologic drugs against malaria.

\section{Conclusions}

The malaria parasite is a very versatile pathogen allowing it to escape from the immune system and kill many people each year. New malaria infections are possible, for example the emergence in Malaysia and surrounding countries of human infection caused by a virulent parasite, P. knowlesi [101]. It is important to focus on elucidation of the basic biology of the parasite-host interaction and the mechanisms of how Plasmodium parasites evade the host immune response and develop resistance to antimalarials. Understanding drug resistance and its prevention is at the top of WHO priorities to fight malaria, complementing parasite elimination programs based on 
pharmacological drugs and insect control. Melatonin has been reported to modulate the Plasmodium cell cycle, but melatonin signaling pathways are complex and activate a subset of genes from the UPS machinery (ubiquitin proteasome system), as well as modulating transcription factor expression. This probably occurs in Plasmodium through activation of second messengers, including $\mathrm{Ca}^{2+}$, cAMP and $\mathrm{IP}_{3}$. Therefore, melatonin signaling pathways represent new ways to understand, dissect and combat the malaria parasite, encompassing the idea of using melatonin antagonists as antimalarial drugs (see reviews [85,102]).

\section{Acknowledgments}

We thank Fundação de Amparo à pesquisa de São Paulo (FAPESP), INCT-InBeqmedi and Pronex-Malaria for funding C.R.S.G.; W.R.L. received a fellowship from FAPESP. A.A.H. is funded by the MRC (U117532067) and the EU FP7 grant agreement 242095 (EviMalar).

\section{Conflict of Interest}

The authors declare no conflict of interest.

\section{References}

1. Hempelmann, E.; Tesarowicz, I.; Oleksyn, B.J. From onions to artemisinin. Brief history of malaria chemotherapy. Pharm. Unserer Zeit 2009, 38, 500-507.

2. World Malaria Report 2012. Available online: http://www.who.int/malaria/publications/ world_malaria_report_2012/en/index.html (accessed on 19 April 2013).

3. Khan, S.M.; Waters, A.P. Malaria parasite transmission stages: An update. Trends Parasitol. 2004, 20, 575-580.

4. Bannister, L.H.; Hopkins, J.M.; Fowler, R.E.; Krishna, S.; Mitchell, G.H. A brief illustrated guide to the ultrastructure of Plasmodium falciparum asexual blood stages. Parasitol. Today 2000, 16, 427-433.

5. Garcia, C.R.; de Azevedo, M.F.; Wunderlich, G.; Budu, A.; Young, J.A.; Bannister, L. Plasmodium in the postgenomic era: New insights into the molecular cell biology of malaria parasites. Int. Rev. Cell Mol. Biol. 2008, 266, 85-156.

6. Mita-Mendoza, N.K.; van de Hoef, D.L.; Lopera-Mesa, T.M.; Doumbia, S.; Konate, D.; Doumbouya, M.; Gu, W.; Anderson, J.M.; Santos-Argumedo, L.; Rodriguez, A.; et al. A potential role for plasma uric acid in the endothelial pathology of Plasmodium falciparum malaria. PLoS One 2013, 8, e54481.

7. White, N.J.; Warrell, D.A.; Looareesuwan, S.; Chanthavanich, P.; Phillips, R.E.; Pongpaew, P. Pathophysiological and prognostic significance of cerebrospinal-fluid lactate in cerebral malaria. Lancet 1985, 1, 776-778.

8. Reis, P.A.; Estato, V.; da Silva, T.I.; d'Avila, J.C.; Siqueira, L.D.; Assis, E.F.; Bozza, P.T.; Bozza, F.A.; Tibirica, E.V.; Zimmerman, G.A.; et al. Statins decrease neuroinflammation and prevent cognitive impairment after cerebral malaria. PLoS Pathog. 2012, 8, e1003099. 
9. Hawking, F.; Worms, M.J.; Gammage, K. 24- and 48-hour cycles of malaria parasites in the blood; their purpose, production and control. Trans. R. Soc. Trop. Med. Hyg. 1968, 62, 731-765.

10. Newbold, C.I.; Boyle, D.B.; Smith, C.C.; Brown, K.N. Stage specific protein and nucleic acid synthesis during the asexual cycle of the rodent malaria Plasmodium chabaudi. Mol. Biochem. Parasitol. 1982, 5, 33-44.

11. Gardner, M.J.; Hall, N.; Fung, E.; White, O.; Berriman, M.; Hyman, R.W.; Carlton, J.M.; Pain, A.; Nelson, K.E.; Bowman, S.; et al. Genome sequence of the human malaria parasite Plasmodium falciparum. Nature 2002, 419, 498-511.

12. Grover, M.; Chaubey, S.; Ranade, S.; Tatu, U. Identification of an exported heat shock protein 70 in Plasmodium falciparum. Parasite 2013, 20, 1-9.

13. Cai, H.; Hong, C.; Gu, J.; Lilburn, T.G.; Kuang, R.; Wang, Y. Module-based subnetwork alignments reveal novel transcriptional regulators in malaria parasite Plasmodium falciparum. BMC Syst. Biol. 2012, 6, S5, doi:10.1186/1752-0509-6-S3-S5.

14. Doerig, C.; Baker, D.; Billker, O.; Blackman, M.J.; Chitnis, C.; Dhar Kumar, S.; Heussler, V.; Holder, A.A.; Kocken, C.; Krishna, S.; et al. Signalling in malaria parasites. The MALSIG consortium. Parasite 2009, 16, 169-182.

15. Pandi-Perumal, S.R.; Srinivasan, V.; Maestroni, G.J.; Cardinali, D.P.; Poeggeler, B.; Hardeland, R. Melatonin: Nature's most versatile biological signal? FEBS J. 2006, 273, 2813-2838.

16. Jan, J.E.; Reiter, R.J.; Wasdell, M.B.; Bax, M. The role of the thalamus in sleep, pineal melatonin production, and circadian rhythm sleep disorders. J. Pineal. Res. 2009, 46, 1-7.

17. Reiter, R.J.; Paredes, S.D.; Manchester, L.C.; Tan, D.X. Reducing oxidative/nitrosative stress: A newly-discovered genre for melatonin. Crit. Rev. Biochem. Mol. Biol. 2009, 44, 175-200.

18. Ben-Nathan, D.; Maestroni, G.J.; Lustig, S.; Conti, A. Protective effects of melatonin in mice infected with encephalitis viruses. Arch. Virol. 1995, 140, 223-230.

19. Bonilla, E.; Valero, N.; Chacin-Bonilla, L.; Medina-Leendertz, S. Melatonin and viral infections. J. Pineal. Res. 2004, 36, 73-79.

20. McNulty, S.; Ross, A.W.; Barrett, P.; Hastings, M.H.; Morgan, P.J. Melatonin regulates the phosphorylation of CREB in ovine pars tuberalis. J. Neuroendocrinol. 1994, 6, 523-532.

21. Dubbels, R.; Reiter, R.J.; Klenke, E.; Goebel, A.; Schnakenberg, E.; Ehlers, C.; Schiwara, H.W.; Schloot, W. Melatonin in edible plants identified by radioimmunoassay and by high performance liquid chromatography-mass spectrometry. J. Pineal. Res. 1995, 18, 28-31.

22. Paredes, S.D.; Korkmaz, A.; Manchester, L.C.; Tan, D.X.; Reiter, R.J. Phytomelatonin: A review. J. Exp. Bot. 2009, 60, 57-69.

23. Balzer, I.; Hardeland, R. Photoperiodism and effects of indoleamines in a unicellular alga, Gonyaulax polyedra. Science 1991, 253, 795-797.

24. Hardeland, R.; Balzer, I.; Poeggeler, B.; Fuhrberg, B.; Uria, H.; Behrmann, G.; Wolf, R.; Meyer, T.J.; Reiter, R.J. On the primary functions of melatonin in evolution: Mediation of photoperiodic signals in a unicell, photooxidation, and scavenging of free radicals. J. Pineal. Res. 1995, 18, 104-111.

25. Yamada, Y.; Forger, D. Multiscale complexity in the mammalian circadian clock. Curr. Opin. Genet. Dev. 2010, 20, 626-633. 
26. Reppert, S.M.; Weaver, D.R. Coordination of circadian timing in mammals. Nature 2002, 418, 935-941.

27. Golombek, D.A.; Rosenstein, R.E. Physiology of circadian entrainment. Physiol. Rev. 2010, 90, 1063-1102.

28. Agez, L.; Laurent, V.; Guerrero, H.Y.; Pevet, P.; Masson-Pevet, M.; Gauer, F. Endogenous melatonin provides an effective circadian message to both the suprachiasmatic nuclei and the pars tuberalis of the rat. J. Pineal. Res. 2009, 46, 95-105.

29. Hotta, C.T.; Gazarini, M.L.; Beraldo, F.H.; Varotti, F.P.; Lopes, C.; Markus, R.P.; Pozzan, T.; Garcia, C.R. Calcium-dependent modulation by melatonin of the circadian rhythm in malarial parasites. Nat. Cell Biol. 2000, 2, 466-468.

30. Hotta, C.T.; Markus, R.P.; Garcia, C.R. Melatonin and N-acetyl-serotonin cross the red blood cell membrane and evoke calcium mobilization in malarial parasites. Braz. J. Med. Biol. Res. 2003, 36, 1583-1587.

31. Beraldo, F.H.; Garcia, C.R. Products of tryptophan catabolism induce $\mathrm{Ca}^{2+}$ release and modulate the cell cycle of Plasmodium falciparum malaria parasites. J. Pineal. Res. 2005, 39, 224-230.

32. Budu, A.; Peres, R.; Bueno, V.B.; Catalani, L.H.; Garcia, C.R. N1-acetyl-N2-formyl-5methoxykynuramine modulates the cell cycle of malaria parasites. J. Pineal Res. 2007, 42, 261-266.

33. Alves, E.; Bartlett, P.J.; Garcia, C.R.; Thomas, A.P. Melatonin and IP3-induced $\mathrm{Ca}^{2+}$ release from intracellular stores in the malaria parasite Plasmodium falciparum within infected red blood cells. J. Biol. Chem. 2011, 286, 5905-5912.

34. Beraldo, F.H.; Almeida, F.M.; da Silva, A.M.; Garcia, C.R. Cyclic AMP and calcium interplay as second messengers in melatonin-dependent regulation of Plasmodium falciparum cell cycle. J. Cell Biol. 2005, 170, 551-557.

35. Syin, C.; Parzy, D.; Traincard, F.; Boccaccio, I.; Joshi, M.B.; Lin, D.T.; Yang, X.M.; Assemat, K.; Doerig, C.; Langsley, G. The H89 cAMP-dependent protein kinase inhibitor blocks Plasmodium falciparum development in infected erythrocytes. Eur. J. Biochem. 2001, 268, 4842-4849.

36. Rached, F.B.; Ndjembo-Ezougou, C.; Chandran, S.; Talabani, H.; Yera, H.; Dandavate, V.; Bourdoncle, P.; Meissner, M.; Tatu, U.; Langsley, G. Construction of a Plasmodium falciparum Rab-interactome identifies CK1 and PKA as Rab-effector kinases in malaria parasites. Biol. Cell. 2012, 104, 34-47.

37. Merckx, A.; Bouyer, G.; Thomas, S.L.; Langsley, G.; Egee, S. Anion channels in Plasmodium-falciparum-infected erythrocytes and protein kinase A. Trends Parasitol. 2009, 25, 139-144.

38. Lasonder, E.; Green, J.L.; Camarda, G.; Talabani, H.; Holder, A.A.; Langsley, G.; Alano, P. The Plasmodium falciparum schizont phosphoproteome reveals extensive phosphatidylinositol and cAMP-protein kinase A signaling. J. Proteome Res. 2012, 11, 5323-5337.

39. Holder, A.A.; Mohd Ridzuan, M.A.; Green, J.L. Calcium dependent protein kinase 1 and calcium fluxes in the malaria parasite. Microb. Infect. 2012, 14, 825-830.

40. Berridge, M.J. Inositol trisphosphate and calcium signalling mechanisms. Biochim. Biophys. Acta 2009, 1793, 933-940. 
41. Ishino, T.; Orito, Y.; Chinzei, Y.; Yuda, M. A calcium-dependent protein kinase regulates Plasmodium ookinete access to the midgut epithelial cell. Mol. Microbiol. 2006, 59, 1175-1184.

42. Ono, T.; Cabrita-Santos, L.; Leitao, R.; Bettiol, E.; Purcell, L.A.; Diaz-Pulido, O.; Andrews, L.B.; Tadakuma, T.; Bhanot, P.; Mota, M.M.; et al. Adenylyl cyclase alpha and cAMP signaling mediate Plasmodium sporozoite apical regulated exocytosis and hepatocyte infection. PLoS Pathog. 2008, 4, e1000008.

43. Alleva, L.M.; Kirk, K. Calcium regulation in the intraerythrocytic malaria parasite Plasmodium falciparum. Mol. Biochem. Parasitol. 2001, 117, 121-128.

44. Biagini, G.A.; Bray, P.G.; Spiller, D.G.; White, M.R.; Ward, S.A. The digestive food vacuole of the malaria parasite is a dynamic intracellular $\mathrm{Ca}^{2+}$ store. J. Biol. Chem. 2003, 278, 27910-27915.

45. Billker, O.; Lourido, S.; Sibley, L.D. Calcium-dependent signaling and kinases in apicomplexan parasites. Cell Host Microb. 2009, 5, 612-622.

46. Valderramos, S.G.; Scanfeld, D.; Uhlemann, A.C.; Fidock, D.A.; Krishna, S. Investigations into the role of the Plasmodium falciparum SERCA (PfATP6) L263E mutation in artemisinin action and resistance. Antimicrob. Agents Chemotherap. 2010, 54, 3842-3852.

47. Agarwal, S.; Singh, M.K.; Garg, S.; Chitnis, C.E.; Singh, S. Ca(2+) -mediated exocytosis of subtilisin-like protease 1: A key step in egress of Plasmodium falciparum merozoites. Cell. Microbiol. 2012, doi:10.1111/cmi.12086.

48. Beraldo, F.H.; Mikoshiba, K.; Garcia, C.R. Human malarial parasite, Plasmodium falciparum, displays capacitative calcium entry: 2-aminoethyl diphenylborinate blocks the signal transduction pathway of melatonin action on the P. falciparum cell cycle. J. Pineal. Res. 2007, 43, 360-364.

49. Hershko, A.; Ciechanover, A. The ubiquitin system. Annu. Rev. Biochem. 1998, 67, 425-479.

50. Glickman, M.H.; Ciechanover, A. The ubiquitin-proteasome proteolytic pathway: Destruction for the sake of construction. Physiol. Rev. 2002, 82, 373-428.

51. Ciechanover, A.; Schwartz, A.L. The ubiquitin-proteasome pathway: The complexity and myriad functions of proteins death. Proc. Natl. Acad. Sci. USA 1998, 95, 2727-2730.

52. Baumeister, W.; Walz, J.; Zuhl, F.; Seemuller, E. The proteasome: Paradigm of a self-compartmentalizing protease. Cell 1998, 92, 367-380.

53. Voges, D.; Zwickl, P.; Baumeister, W. The 26S proteasome: A molecular machine designed for controlled proteolysis. Annu. Rev. Biochem. 1999, 68, 1015-1068.

54. Naujokat, C.; Hoffmann, S. Role and function of the $26 \mathrm{~S}$ proteasome in proliferation and apoptosis. Lab. Investig. J. Tech. Methods Pathol. 2002, 82, 965-980.

55. Rock, K.L.; York, I.A.; Saric, T.; Goldberg, A.L. Protein degradation and the generation of MHC class I-presented peptides. Adv. Immunol. 2002, 80, 1-70.

56. Kruger, E.; Kuckelkorn, U.; Sijts, A.; Kloetzel, P.M. The components of the proteasome system and their role in MHC class I antigen processing. Rev. Physiol. Biochem. Pharmacol. 2003, 148, 81-104.

57. Wolf, D.H.; Hilt, W. The proteasome: A proteolytic nanomachine of cell regulation and waste disposal. Biochim. Biophys. Acta 2004, 1695, 19-31.

58. Goldberg, A.L. Protein degradation and protection against misfolded or damaged proteins. Nature 2003, 426, 895-899. 
59. Cardozo, T.; Pagano, M. The SCF ubiquitin ligase: Insights into a molecular machine. Nature Rev. Mol. Cell Biol. 2004, 5, 739-751.

60. Chung, D.W.; Ponts, N.; Prudhomme, J.; Rodrigues, E.M.; Le Roch, K.G. Characterization of the ubiquitylating components of the human malaria parasite's protein degradation pathway. PLoS One 2012, 7, e43477.

61. Ponder, E.L.; Bogyo, M. Ubiquitin-like modifiers and their deconjugating enzymes in medically important parasitic protozoa. Eukaryot. Cell 2007, 6, 1943-1952.

62. Ponts, N.; Yang, J.; Chung, D.W.; Prudhomme, J.; Girke, T.; Horrocks, P.; Le Roch, K.G. Deciphering the ubiquitin-mediated pathway in apicomplexan parasites: A potential strategy to interfere with parasite virulence. PLoS One 2008, 3, e2386.

63. Schneider, A.; Haas, S.L.; Hildenbrand, R.; Siegmund, S.; Reinhard, I.; Nakovics, H.; Singer, M.V.; Feick, P. Enhanced expression of interleukin-18 in serum and pancreas of patients with chronic pancreatitis. World J. Gastroenterol. 2006, 12, 6507-6514.

64. Dharmasiri, N.; Dharmasiri, S.; Estelle, M. The F-box protein TIR1 is an auxin receptor. Nature 2005, 435, 441-445.

65. Kepinski, S.; Leyser, O. The Arabidopsis F-box protein TIR1 is an auxin receptor. Nature 2005, 435, 446-451.

66. Murch, S.; Saxena, P.K. Melatonin: A potential regulator of plant growth and development? In Vitro Cell Dev. Biol. Plant 2002, 38, 531-536.

67. Schroder, R.; Abele, C.; Gohr, P.; Stuhlfauth-Roisch, U.; Grosse, W. Latest on enzymology of serotonin biosynthesis in walnut seeds. In Tryptophan, Seronin and Melatonin: Basic Aspects and Applications; Huether, G., Kochen, W., Simat, T.J., Steinhart, H., Eds.; Kluwer Academic Publishers: Dordrecht, The Netherlands, 1999; Volume 467, pp. 637-644.

68. Koyama, F.C.; Ribeiro, R.Y.; Garcia, J.L.; Azevedo, M.F.; Chakrabarti, D.; Garcia, C.R. Ubiquitin proteasome system and the atypical kinase PfPK7 are involved in melatonin signaling in Plasmodium falciparum. J. Pineal. Res. 2012, 165, 1-7.

69. Dorin, D.; Semblat, J.P.; Poullet, P.; Alano, P.; Goldring, J.P.; Whittle, C.; Patterson, S.; Chakrabarti, D.; Doerig, C. PfPK7, an atypical MEK-related protein kinase, reflects the absence of classical three-component MAPK pathways in the human malaria parasite Plasmodium falciparum. Mol. Microbiol. 2005, 55, 184-196.

70. Doerig, C.; Abdi, A.; Bland, N.; Eschenlauer, S.; Dorin-Semblat, D.; Fennell, C.; Halbert, J.; Holland, Z.; Nivez, M.P.; Semblat, J.P.; et al. Malaria: Targeting parasite and host cell kinomes. Biochim. Biophys. Acta 2010, 1804, 604-612.

71. Chang, C.F.; Huang, H.J.; Lee, H.C.; Hung, K.C.; Wu, R.T.; Lin, A.M. Melatonin attenuates kainic acid-induced neurotoxicity in mouse hippocampus via inhibition of autophagy and alpha-synuclein aggregation. J. Pineal Res. 2012, 52, 312-321.

72. Luchetti, F.; Canonico, B.; Betti, M.; Arcangeletti, M.; Pilolli, F.; Piroddi, M.; Canesi, L.; Papa, S.; Galli, F. Melatonin signaling and cell protection function. FASEB J. 2010, 24, 3603-3624.

73. Tomas-Zapico, C.; Coto-Montes, A. A proposed mechanism to explain the stimulatory effect of melatonin on antioxidative enzymes. J. Pineal. Res. 2005, 39, 99-104. 
74. Yoo, Y.M.; Jung, E.M.; Choi, K.C.; Jeung, E.B. Effect of melatonin on mRNA expressions of transcription factors in murine embryonic stem cells. Brain Res. 2011, 1385, 1-7.

75. Lima, W.R.; Moraes, M.; Alves, E.; Azevedo, M.F.; Passos, D.O.; Garcia, C.R. The PfNF-YB transcription factor is a downstream target of melatonin and cAMP signalling in the human malaria parasite Plasmodium falciparum. J. Pineal. Res. 2013, 54, 145-153.

76. Dorn, A.; Bollekens, J.; Staub, A.; Benoist, C.; Mathis, D. A multiplicity of CCAAT box-binding proteins. Cell 1987, 50, 863-872.

77. Maity, S.N.; de Crombrugghe, B. Role of the CCAAT-binding protein CBF/NF-Y in transcription. Trends Biochem. Sci. 1998, 23, 174-178.

78. Kao, C.Y.; Tanimoto, A.; Arima, N.; Sasaguri, Y.; Padmanabhan, R. Transactivation of the human $\mathrm{CDC} 2$ promoter by adenovirus E1A. E1A induces the expression and assembly of a heteromeric complex consisting of the CCAAT box binding factor, CBF/NF-Y, and a $110-\mathrm{kDa}$ DNA-binding protein. J. Biol. Chem. 1999, 274, 23043-23051.

79. $\mathrm{Hu}, \mathrm{Q}$.; Bhattacharya, C.; Maity, S.N. CCAAT binding factor (CBF) binding mediates cell cycle activation of topoisomerase IIalpha. Conventional CBF activation domains are not required. J. Biol. Chem. 2002, 277, 37191-37200.

80. Klein, D.C.; Coon, S.L.; Roseboom, P.H.; Weller, J.L.; Bernard, M.; Gastel, J.A.; Zatz, M.; Iuvone, P.M.; Rodriguez, I.R.; Begay, V.; et al. The melatonin rhythm-generating enzyme: Molecular regulation of serotonin $\mathrm{N}$-acetyltransferase in the pineal gland. Recent Prog. Horm. Res. 1997, 52, 307-357;

81. Johnston, J.D.; Bashforth, R.; Diack, A.; Andersson, H.; Lincoln, G.A.; Hazlerigg, D.G. Rhythmic melatonin secretion does not correlate with the expression of arylalkylamine $N$-acetyltransferase, inducible cyclic amp early repressor, period1 or cryptochrome1 mRNA in the sheep pineal. Neuroscience 2004, 124, 789-795.

82. Sugden, L.A.; Sugden, D.; Klein, D.C. Alpha 1-adrenoceptor activation elevates cytosolic calcium in rat pinealocytes by increasing net influx. J. Biol. Chem. 1987, 262, 741-745.

83. Schomerus, C.; Laedtke, E.; Korf, H.W. Calcium responses of isolated, immunocytochemically identified rat pinealocytes to noradrenergic, cholinergic and vasopressinergic stimulations. Neurochem. Int. 1995, 27, 163-175.

84. Gastel, J.A.; Roseboom, P.H.; Rinaldi, P.A.; Weller, J.L.; Klein, D.C. Melatonin production: Proteasomal proteolysis in serotonin N-acetyltransferase regulation. Science 1998, 279, 1358-1360.

85. Srinivasan, V.; Spence, D.W.; Moscovitch, A.; Pandi-Perumal, S.R.; Trakht, I.; Brown, G.M.; Cardinali, D.P. Malaria: Therapeutic implications of melatonin. J. Pineal. Res. 2010, 48, 1-8.

86. Reppert, S.M.; Weaver, D.R.; Ebisawa, T. Cloning and characterization of a mammalian melatonin receptor that mediates reproductive and circadian responses. Neuron 1994, 13, 1177-1185.

87. Reppert, S.M.; Godson, C.; Mahle, C.D.; Weaver, D.R.; Slaugenhaupt, S.A.; Gusella, J.F. Molecular characterization of a second melatonin receptor expressed in human retina and brain: The Mellb melatonin receptor. Proc. Natl. Acad. Sci. USA 1995, 92, 8734-8738.

88. Reppert, S.M.; Weaver, D.R.; Ebisawa, T.; Mahle, C.D.; Kolakowski, L.F., Jr. Cloning of a melatonin-related receptor from human pituitary. FEBS Lett. 1996, 386, 219-224. 
89. Levoye, A.; Dam, J.; Ayoub, M.A.; Guillaume, J.L.; Couturier, C.; Delagrange, P.; Jockers, R. The orphan GPR50 receptor specifically inhibits MT1 melatonin receptor function through heterodimerization. EMBO J. 2006, 25, 3012-3023.

90. Dubocovich, M.L.; Yun, K.; Al-Ghoul, W.M.; Benloucif, S.; Masana, M.I. Selective MT2 melatonin receptor antagonists block melatonin-mediated phase advances of circadian rhythms. FASEB J. 1998, 12, 1211-1220.

91. Smirnov, A.N. Nuclear melatonin receptors. Biochem. Biokhimiia 2001, 66, 19-26.

92. Garcia-Perganeda, A.; Guerrero, J.M.; Rafii-El-Idrissi, M.; Paz Romero, M.; Pozo, D.; Calvo, J.R. Characterization of membrane melatonin receptor in mouse peritoneal macrophages: Inhibition of adenylyl cyclase by a pertussis toxin-sensitive G protein. J. Neuroimmunol. 1999, 95, 85-94.

93. Browning, C.; Beresford, I.; Fraser, N.; Giles, H. Pharmacological characterization of human recombinant melatonin MT(1) and MT(2) receptors. Br. J. Pharmacol. 2000, 129, 877-886.

94. Dubocovich, M.L.; Cardinali, D.P.; Guardiola-Lemaitre, B.; Hagan, R.M.; Krause, D.N.; Sugden, D. Melatonin receptors. In The IUPHAR Compendium of Receptor Characterization and Classification, 2nd ed.; IUPHAR Media: London, UK, 2000; pp. 271-277.

95. Bagnaresi, P.; Markus, R.P.; Hotta, C.T.; Pozzan, T.; Garcia, C.R. Desynchronizing Plasmodium cell cycle increases chloroquine protection at suboptimal doses. Open Parasitol. J. 2008, 2, 55-58.

96. Gazarini, M.L.; Garcia, C.R. The malaria parasite mitochondrion senses cytosolic $\mathrm{Ca}^{2+}$ fluctuations. Biochem. Biophys. Res. Commun. 2004, 321, 138-144.

97. Guha, M.; Maity, P.; Choubey, V.; Mitra, K.; Reiter, R.J.; Bandyopadhyay, U. Melatonin inhibits free radical-mediated mitochondrial-dependent hepatocyte apoptosis and liver damage induced during malarial infection. J. Pineal. Res. 2007, 43, 372-381.

98. Bagnaresi, P.; Alves, E.; da Silva, H.B.; Epiphanio, S.; Mota, M.M.; Garcia, C.R. Unlike the synchronous Plasmodium falciparum and P. chabaudi infection, the P. berghei and $P$. yoelii asynchronous infections are not affected by melatonin. Int. J. Gen. Med. 2009, 2, 47-55.

99. O’Donnell, A.J.; Schneider, P.; McWatters, H.G.; Reece, S.E. Fitness costs of disrupting circadian rhythms in malaria parasites. Proc. Biol. Sci. 2011, 278, 2429-2436.

100. Mideo, N.; Reece, S.E.; Smith, A.L.; Metcalf, C.J. The Cinderella syndrome: Why do malaria-infected cells burst at midnight? Trends Parasitol. 2013, 29, 10-16.

101. Srinivasan, V.; Mohamed, M.; Zakaria, R.; Ahmad, A.H. Malaria, anti malarial drugs and the role of melatonin. Infect. Disord. Drug Targets 2012, 12, 371-379.

102. Srinivasan, V.; Ahmad, A.H.; Mohamed, M.; Zakaria, R. Melatonin effects on Plasmodium life cycle: New avenues for therapeutic approach. Recent Pat. Endocr. Metab. Immune Drug Discov. 2012, 6, 139-147.

(C) 2013 by the authors; licensee MDPI, Basel, Switzerland. This article is an open access article distributed under the terms and conditions of the Creative Commons Attribution license (http://creativecommons.org/licenses/by/3.0/). 